\title{
Implicancias del rol de cuidado en la vida de las mujeres responsables de personas dependientes por discapacidad que, en el 2015, asistieron al Programa Educativo para Niños con Discapacidad Física, en Asunción
}

\section{Implications of the role of caring for the lives of the responsible people of people dependent on disability who, in 2015, assisted in the Educational Program for Children with Physical Disabilities in Asunción}

\author{
Romilio González Chamorro ${ }^{a}$
}

\begin{abstract}
Resumen
El cuidado, es una necesidad y un derecho durante todas las etapas del desarrollo del ser humano, es realizado mayoritariamente por las mujeres, pero es desvalorizado social y económicamente en sociedades patriarcales, perjudicando el ejercicio de sus derechos y su ciudadanía social. Desde el concepto de la organización social del cuidado, esta investigación tiene por objetivo, analizar la incidencia de factores socioculturales en el imaginario y en las prácticas de las mujeres en relación a su rol de cuidado de niñas y niños con discapacidad física que, en el año 2015, asistieron al Programa Educativo para Niños con Discapacidad Física en Asunción. Es de tipo exploratorio, de carácter cualitativo y con muestreo por conveniencia. Se utilizan entrevistas en profundidad con una guía de preguntas. Se utilizó una matriz de categorías y la técnica del análisis de discursos para el análisis. Los resultados obtenidos muestran que, los imaginarios y las prácticas sociales de las mujeres entrevistadas, están influenciadas por representaciones sociales basadas en la división sexual del trabajo con las que explican, justifican y refuerzan el reparto tradicional de los roles de cuidados, lo que implicó para ellas, el aumento de su tiempo total de trabajo en perjuicio de su bienestar. Para sobrellevarlo, sus estrategias de resistencias son de carácter personal, y desarticuladas de servicios públicos u organizativos. En conclusión, estas mujeres, por influencia de la división sexual del trabajo asocian la maternidad y los cuidados como sus funciones naturales e ineludibles, asumiendo
\end{abstract}

a Universidad Nacional de Asunción, Facultad de Ciencias Sociales, Paraguay.

Correspondencia a: romiliogch@gmail.com

Recibido:

18 agosto 2019

Aceptado:

30 noviembre 2019

Artículo publicado en acceso abierto bajo la Licencia Creative Commons.

c) (i)

Cita:

González Chamorro, R. (2019). Implicancias del rol de cuidado en la vida de las mujeres responsables de personas dependientes por discapacidad que, en el 2015, asistieron al Programa Educativo para Niños con

Discapacidad Física, en Asunción. Kera Yvoty: reflexiones sobre la cuestión social, 4, 102-112. 
la sobrecarga de los cuidados, privilegiando a los hombres y la acumulación. Si esto no se revierte, se seguirá perjudicando el bienestar principalmente de las mujeres.

Palabras clave: cuidados, género, organización social del cuidado.

\begin{abstract}
Care is a necessity and an end during all stages of the development of the human being, it is carried out mainly by the women, but is socially and economically devalued in patriarchal societies, undermining the exercise of their derechos and their social citizenship. From the concept of the social organization of care, this research has as its objective, to analyze the incidence of sociocultural factors in the imagination and the practices of women in relation to their care of children and children with physical disability which, in their Year 2015, Assisted the Educational Program for Children with Physical Disability in Asunción. They are exploratory in nature, qualitative in nature and convenient for convenience. If interviews are used depth with a guide of questions. A matrix of categories and discourse analysis technique is used for analysis. The results obtained, however, are that the imaginary and social practices of the women interviewed are influenced by social representations based on the sexual division of the work that explains, justifies and refers the traditional sharing of the roles of care, what it implies for them. They increase your total time of work in the health of your wellbeing. To top it off, his strategies of sound resistance are personal in character, and disjointed from public or organizational services. In conclusion, these women, influenced by the sexual division of work associated with motherhood and care as their natural and ineludable functions, assume the burden of care, privileging men and accumulation. If they are not reversed, it will continue to undermine the bienestar mainly of the women.
\end{abstract}

Keywords: care, gender, social organization of care.

\section{Introducción}

El cuidado, es decir, cuidar y ser cuidado, es una necesidad y un derecho durante todas las etapas del desarrollo del ser humano, es una actividad fundamental para la reproducción del ser humano y de las economías (Soto, González, \& Dobrée, 2012a; Ezquivel, 2011; Castro, 2012; Espino, \& Sanchís, 2012; Rodríguez, 2008).

Los cuidados son aún más necesarios para aquellas personas dependientes por discapacidad, edad o enfermedad. Sin en embargo, en las sociedades patriarcales sostenidas en base a la división sexual del trabajo, el trabajo reproductivo de los cuidados realizado por las mujeres es desvalorizado social y económicamente, pero aprovechado por el sistema económico capitalista en beneficio y privilegio de los hombres (Ezquivel, 2011; Rodríguez, 2008; Ezquivel, 2012; Soto et al., 2012a; Bagnato, Da Cuna, Falero, (s.f.); Paraguay. Ministerio de Justicia y Trabajo, STP, Ministerio de la Mujer y Vice Ministerio de la Juventud, 2013).

La ausencia de políticas públicas para equilibrar la vida laboral y familiar, perjudican el bienestar y desarrollo integral de la vida de estas mujeres (PNUD, 2011 citado en ONU, PNUD, Cooperazione Italian,(s.f.);ONUMujeres, 2010; Rodríguez, 2008; Batthyány, 2001; Batthyány, 2007; Esquivel, 2011; Esquivel, 2012), afectando directamente el ejercicio de sus derechos y su ciudadanía social (Batthyány, K., 2001). La presente investigación recupera, como marco teórico general (Sautu et al., 2005) el concepto de la organización social del cuidado (ONU Mujeres 2014; Batthyány, 2013; Esquivel, 2012), como marco teórico, poniendo en el centro del debate el cuidado como generador de bienestar pero que a la vez perjudica la salud y vida de las mujeres que lo realizan. 
Desde el 2014, ONU Mujeres define "que los cuidados son las actividades que permiten regenerar día a día el bienestar físico y emocional de las personas. Cuidar es hacerse cargo de los cuerpos de las personas y también de las emociones que los atraviesan" (p. 11).

Agrega que los cuidados implican diversos contenidos como:

Cuidados directos: tareas que implican la interacción directa de las personas para lograr salud física y emocional.

Precondicionesdelcuidado:tareasque establecen las condiciones materiales que hacen posible los cuidados directos. A veces las llamamos trabajo doméstico.

Gestión mental: tareas de coordinación, planificación y supervisión. Aunque es incierto el tiempo que consumen, pueden suponer una fuerte carga mental y emocional. (ONU Mujeres, 2014, p. 11)

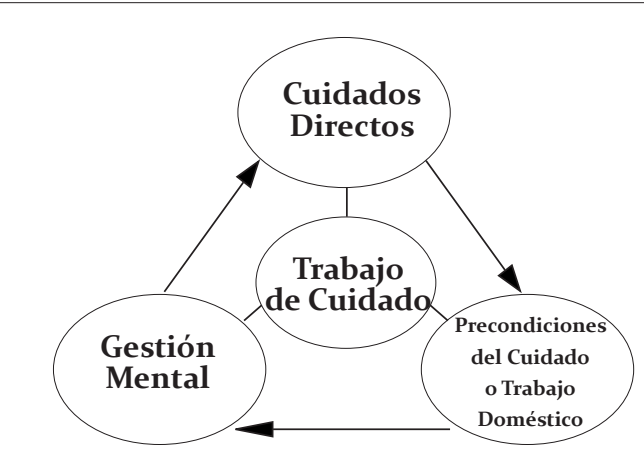

Figura 1: Círculo interdependiente del Trabajo de Cuidado.

Elaboración propia basado en ONU Mujeres (2014).

Relaciones de poder. El poder, entendido como relación de fuerza, se ejerce a partir de una multiplicidad de relaciones que no son igualitarias, "es una acción intencional y está presente en todos los espacios y en toda relación social"
(Foucault, 1981 citado en Piedra, 2004, p. 137).

Cuestión social y resistencia. La cuestión social se expresa y manifiestan en el cotidiano de la vida social, como producto y expresión de la relación contradictoria entre esos dos elementos producto de la expresión contradictoria fundamental entre capital y trabajo históricamente problematizada (Pereira, 2003).

La cuestión social se ha complejizado, como lo sostienen Iamamoto y Netto (citados en Molina, 2007); por tanto, "no hay nueva cuestión social porque es la misma causalidad de la relación capital-trabajo, con expresiones derivadas de una producción cada vez más socializada y una apropiación cada vez más privatizada” (p. 7).

Así también, al mismo tiempo de que la cuestión social es desigualdad "también es rebeldía, por involucrar sujetos que viven las desigualdades, que las resisten y a ellas se oponen" (Iamamoto, 2003, p. 42) los sectores mayoritarios de la población que dependen del trabajo para sobrevivir y que en sus vidas cotidianas crean y activan diferentes formas de resistencias (Iamamoto, 2003).

Para revertir esta desigualdad, es necesario conocer los factores que los motivan a seguir cuidando, cómo hacen estas mujeres para sobrellevar diariamente los cuidados de las personas dependientes y las consecuencias que estas tareas tienen en sus vidas.

\section{Objetivos General}

Analizar la incidencia de factores socioculturales en el imaginario $y$ en las prácticas sociales de las mujeres en relación a su rol de cuidadora de niños y niñas con discapacidad física en situación de dependencia que, en el año 2015, asistieron al Programa Educativo para Niños con Discapacidad Física (PENDIF), en Asunción.

\section{Objetivos Específicos}

- Describir las expresiones e influencias del imaginario $y$ 
de las prácticas sociales en el rol de cuidado de las mujeres responsables de niños y niñas con discapacidad física en situación de dependencia que, en el año 2015, asistieron al Programa Educativo para Niños con Discapacidad Física (PENDIF), en Asunción.

- Identificar las características que presenta la división sexual del trabajo en las relaciones que establecen las mujeres en sus roles de cuidadoras.

- Caracterizar las acciones de resistencias que desarrollan las mujeres en sus vidas cotidianas para sobrellevar los roles de cuidados.

\section{Materiales y Métodos}

La investigación es de tipo exploratorio, de amplitud micro-social y de carácter cualitativo.

Población: La población fue de 33 personas $\left(\begin{array}{lll}\mathrm{H} & \mathrm{y} & \mathrm{M}\end{array}\right)$ encargadas $\mathrm{y} / \mathrm{o}$ responsables del cuidado de niños/as que asistieron en el 2015 al PENDIF, en su mayoría mujeres.

Muestra: Con un muestreo por conveniencia, la muestra fue de casos-tipo (Hernández Sampieri et al.,2006, p. 566), que estuvo conformada por 5 mujeres que dieron información calificada sobre el objeto de estudio, seleccionadas en base a criterios establecidos; mujeres registradas como encargadas, parentesco cercano, vivan en la misma casa con el/la niño/a con discapacidad.

Técnica e instrumento: Se utilizan entrevistas en profundidad con una guía de preguntas. Se utiliza una matriz de categorías y la técnica del análisis de discursos para el análisis de lo relevado.

$$
\text { Aspecto ético: basado en }
$$

el consentimiento informado y la confidencialidad.

\section{Resultados y Discusión}

Deacuerdo a las categorías deanálisis, que son presentados a continuación, los resultados obtenidos muestran que;

\section{Representaciones Sociales y División Sexual del Trabajo}

Los imaginarios y las prácticas sociales de las mujeres entrevistadas con relación a los cuidados están influenciadas por representaciones sociales, que basadas en la división sexual del trabajo, reproducen creencias, figuras e imágenes de la mujer procreadora y maternal mujer bendita, la kuña (mujer) guapa, kuña vale, kuña guerrera y la del serviha (sirvienta) con las queexplican, justificany refuerzanel reparto tradicional de los roles y responsabilidades de cuidados según el sexo, vinculando a las mujeres con el rol reproductivo de procrear y por ende criar y cuidar, naturalizando los cuidados como una función, obligación y un deber ineludible e intransferible de toda madre, mientras que a los hombres se los vincula con el rol productivo de proveedor de los medios económicos de subsistencia y cubrir los costos de cuidados.

$\mathrm{Al}$ respecto las algunas de las mujeres cuidadoras entrevistadas respondieron como sigue. En cuanto a la figuras o imágenes de una Mujer procreadora -bendita y/o Mujer maternal;

Ha isymante la ojeresponsabilizavaerä hese onaseguive. Che obligación ningo, chengo agueru chupe (pcd) ko mundope. Ndikatuiningo ahejaparei che membykuerape. Máva la otro oñatendeta hesekuerare. Itua omba'apo mante arä- $\mathrm{MC}_{1}$

(Su madre es la que debe responsabilizarse desde que nace. Es mi obligación, Yo le (pcd) trabaje al mundo. No les puedo dejar por ahí a mis hijos. Quién más los atenderá. Su padre debe trabajar - $\mathrm{MC}_{1}$ )

Dios nos dio el don de procrear y la fuerza para criar. Es un deber de la madre. Yo, como madre, no puedo 
dejar de cuidarla (hija pcd). Soy la única que le entiende $-\mathrm{MC}_{2}$

En cuanto a la figuras o imágenes del Che serviha (Mi sirvienta) y/o mujer abnegada;

Che mena he'ivoi, la kuña remibapo ningo kuimba'e serviha $\mathrm{MC} 1$

(Mi marido suele decir, que "el trabajo de la mujer es ser la sirvienta del hombre" - MC1)

Koápe rejapova'erã arreirope la cosa (risa nerviosa) - $\mathrm{MC} 1$

(Aquí debes hacerle la cosas (tareas domésticas) al hombre $\mathrm{MC}_{1}$ )

Figura del hombre proveedor;

En mi caso yo le cuido a nuestro hijo (pcd), porque creo que por lo menos su papá es el que debe trabajar y cubrir los gastos - $\mathrm{MC}_{3}$

Ante el abandono de su padre, creo yo que por lo menos debería garantizar la prestación alimentaria para sus hijos $-\mathrm{MC}_{4}$

Características de la división sexual del trabajo en el trabajo de cuidado

En cuanto al rol reproductivo, en las relaciones que las mujeres establecen en su rol de cuidadoras de sus hijos/as dependientes por discapacidad, la división sexual del trabajo se caracteriza por los roles tradicionales, la mayoría de las mujeres asumen como únicas responsables de los cuidados mientras que algunas asumen una responsabilidad principal porque logran delegar ciertas responsabilidades de cuidados y tareas domésticas secundarias a otras mujeres de la familia o el hogar, que por lo general son las abuelas y/o las hijas mayores, pero sin que ellas como madres dejen de asumir las responsabilidades como cuidadoras principales.

Desde que se engendró (pcd), la única responsable siempre fui yo, como toda mamá, nunca transferí su cuidado $-\mathrm{MC}_{4}$

13 años ya tiene mi hija (pcd), durante 12 años que me ayuda su hermana mayor pero yo soy la responsable principal - $\mathrm{MC}_{2}$

Participación de los hombres en rol reproductivo

En cuanto a la participación de los hombres en los cuidados, si bien todos los padres de las persona con discapacidad proveen de los ingresos y sustento económico de sus familias, algunas mujeres denunciaron la ausencia de la corresponsabilidad de los padres para asumir los cuidados de sus hijo y/o hija con discapacidad, mientras que otras declararon que la participación de los hombres, padres e hijos sin discapacidad es marginal (distante), tanto como para asumir responsabilidad de los cuidados así como para realizar las tareas domésticas.

Laconcepciónyasignación deroles, en los cuidados basado en la división sexual del trabajo con las que, según las declaraciones de las mujeres, tanto mujeres y hombres explican y justifican la participación de los hombres como proveedor financiero de los costos de cuidados y que son las mujeres las que deben asumir las responsabilidades y las tareas de los cuidados, son utilizados por los hombres y padres de las personas con discapacidad como un privilegio y como pretexto para desligarse de asumir las responsabilidades y tareas de cuidados.

Ou javengo aheja chupe, ha che asêjave, Ha'e oñenkarga hese, ha upepeve - $\mathrm{MC}_{1}$

(Cuando viene o salgo le dejo, se encarga de él pero solo eso$\mathrm{MC}_{1}$ )

Su papá, no asumió, se borró por un tiempo, después volvió a interesarse en su hijo, nos ayuda económicamente $-\mathrm{MC}_{3}$ 


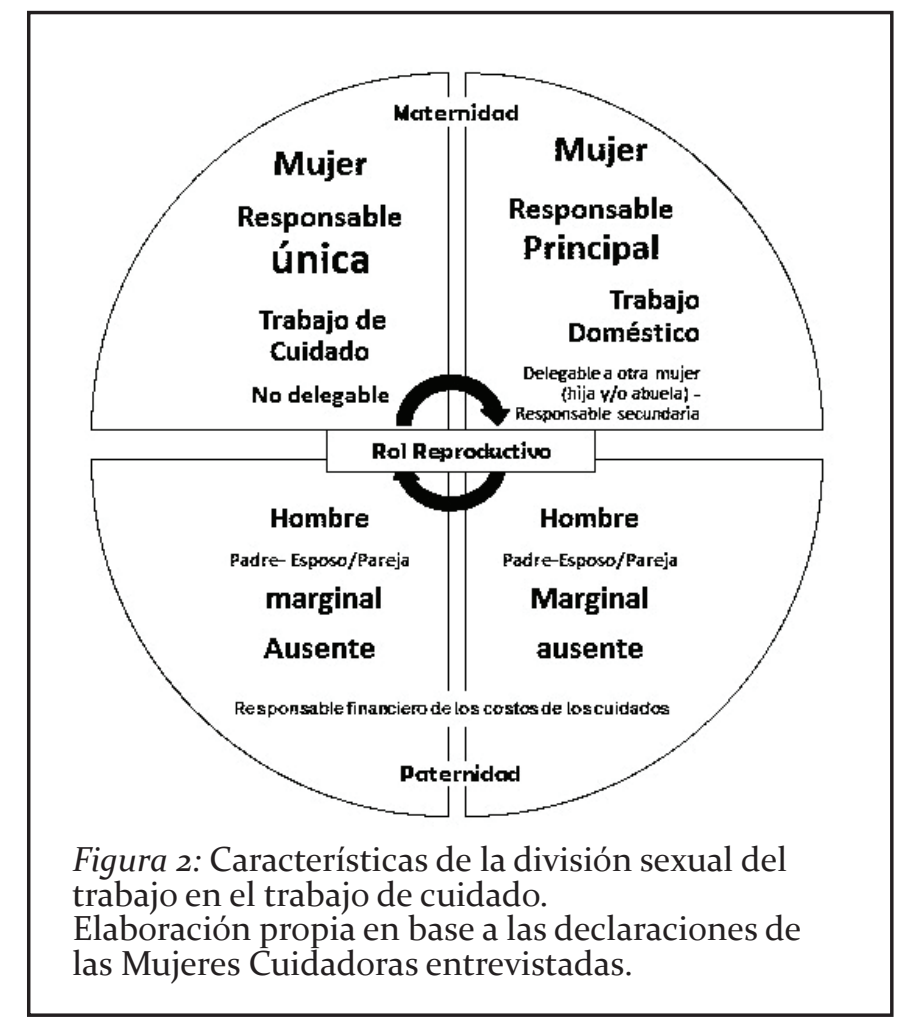

El rol productivo de las mujeres cuidadoras y de los hombres

Aun cuando los hombres de estas familias son los proveedores principales de los ingresos y manutención familiar y la mayoría de las mujeres viven en situación de dependencia económica, estas mujeres también son proveedoras secundarias de los ingresos familiares.

La mayoría de estas mujeres tuvieron que dejar sus trabajos asalariados para dedicar mayor tiempo al cuidado de sus hijos/as con discapacidad, desarrollando actividades comerciales informales por cuenta propia en el hogar y en condiciones precarias, sin seguro social. Una sola de ellas mantuvo su trabajo asalariado en el sector público, con seguro social. Aun así, ninguna de ellas ha dejado de asumir sus responsabilidades ni las tareas de cuidar de sus hijos/as con discapacidad.

Che mena añoite la omba'apoa.
Ome'ê cheve petei monto, ha ndohupytyirô, ajejopyva'i. Areko kua'arã - $\mathrm{MC} 1$

(Mi esposo es el único que trabaja. Me da un monto. Si no me alcanza, me veo en aprietos. Debo saber administrarlo- $\mathrm{MC}_{1}$ )

Hasta ahora yo atiendo mis animales, crio vacas y gallinas, produzco leche, queso y huevos para mi consumo y para la venta, corriendo hago todo, sin desatender a mi hija (pcd) y a mi suegra ya anciana. - $\mathrm{MC}_{2}$

Ese es mi feria de garage. Yo me dedico a vender ropas usadas, también le sirve a mi hijo (pcd) de distracción, él se va ahí como gerente - $\mathrm{MC}_{4}$

Yo deje todo, estaba estudiando para capacitarme en contabilidad. Yo trabajo en una entidad pública, cuando ya no pude cumplir con ese horario agarré el peor turno rotativo de noche, $\mathrm{mi}$ ingreso total bajo $-\mathrm{MC}_{5}$ 
González Chamorro, R. Implicancias del rol de cuidado en la vida de las mujeres responsables de personas dependientes por discapacidad.

\section{Relación de poder}

El concepto foucaultiano del biopoder, ayuda a evidenciar que la división sexual del trabajo opera como dispositivo de poder con la que se asigna a las mujeres el espacio privado-doméstico y la atribución de los trabajos de cuidados como trabajo exclusivo de las mujeres, así como a los hombres el espacio público y el rol productivo, a través de la microfísica del poder, se evidencia que el sacrificio material, es decir, el tiempo dedicado, el esfuerzo realizado y el uso cuerpo de las mujeres cuidadoras, destinados al cuidado de la familia y las personas con discapacidad, es fuerza que justifica y otorga poder de decisión con la que estas mujeres cuidadoras ejercen la conducción de vida familiar como jefas de familia u hogar.

Estos nuevos criterios, construidos por las mujeres y sus familias, son la fuerza con los que, en la práctica, las mujeres cuidadoras hacen uso y ejercen poder de conducción sobre la vida de los miembros de sus familias como jefa del hogar/familia, así también son motivos con los que, desde la dimensión de la vida cotidiana familiar e intimidad del relacionamiento familiar, se generan contradicciones a los mandatos tradicionales basados en la desigual relación biológica entre los sexos, en especial a la tradicional figura de la jefatura del hombre en el hogar. Sin embargo son criterios y prácticas que no logran interpelar la desigual relación de poder, basada en la división sexual del trabajo, en la dimensión socio cultural (nivel macro).

Yo les organizo a ellos, yo tomo la decisión y les comunico nomas ya. Yo administro los gastos $-\mathrm{MC}_{5}$

Yo les organizo las tareas y los horarios. También, yo administro los ingresos, hago maravillas para alcanzar el mes.- $\mathrm{MC}_{4}$

Che a maneja la plata omea cheve, areko kua'arã, ofaltarö, rojejopy vaipaite- $M C_{1}$

(Yo manejo la plata que él me da, debo saber administrar, si falta, nos vemos en un muy mal aprieto - $\mathrm{MC}$ )

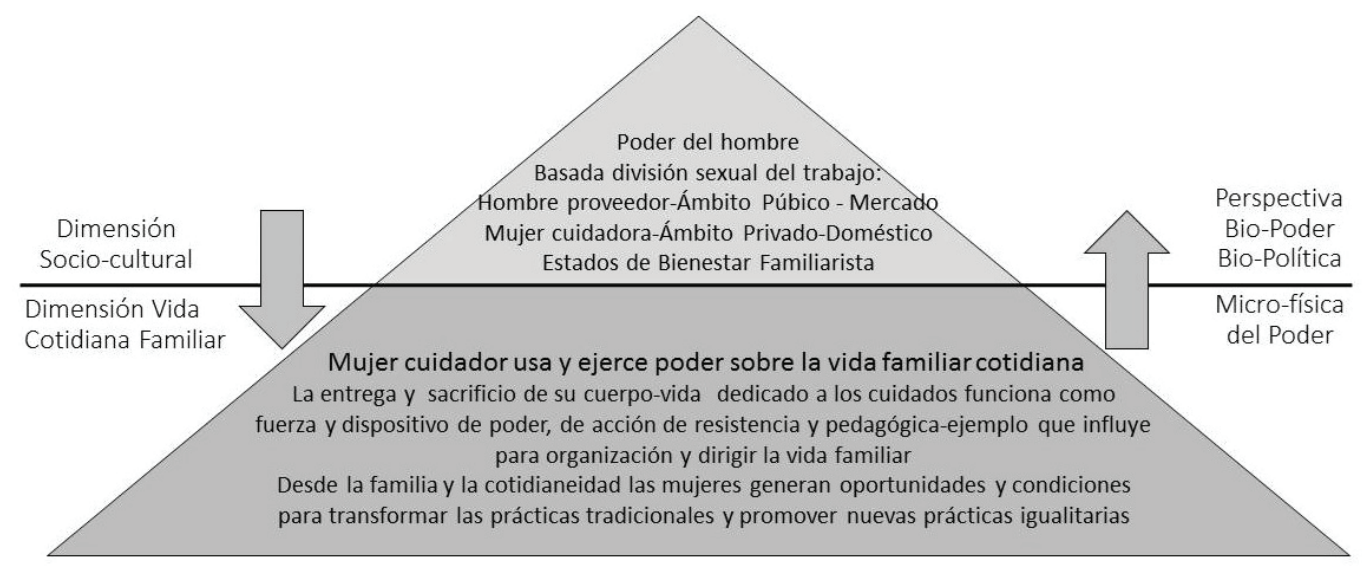

Figura 3. Relaciones de Poder en los cuidados de las personas dependientes por discapacidad. Elaboración propia a partir de conceptos de las relaciones de poder Foucault citados en Piedra Guillen, 2004, p. 137-139, y en base a los resultados analizados de las entrevistas a mujeres cuidadoras. 
La expresión de la cuestión social con relación al trabajo de cuidado

El bienestar de las mujeres cuidadoras se ve deteriorado debido a la sobrecarga del trabajo de cuidado que asumen, mayormente, sin la ayuda de los hombres, de otros miembros de la familia, el Estado, el mercado y la comunidad.

El sistema capitalista aliado al sistema patriarcal en las sociedades que construyen social y culturalmente sus relaciones de género y sus relaciones de poder sustentados en la división sexual del trabajo, aumenta la acumulación capitalista valiéndose del trabajo de los cuidados que, atribuido a lo femenino, es desvalorizado social, cultural y económicamente, que sin muchas opciones de elegir por voluntad propia es realizado, mayoritariamente, por mujeres y de manera gratuita.

En este contexto, la cuestión social, se expresa en tanto el trabajo de cuidado como actividad humana realizado histórica y mayoritariamente por las mujeres, es un trabajo que genera bienestar para la vida de las personas cuidadas, garantiza la reproducción de la fuerza de trabajo, genera valor para las economías y contribuye a la acumulación capitalista pero contradictoriamente el trabajo femenino de los cuidado es desvalorizado social, cultural, histórica y económicamente, es realizado condiciones desiguales y precarias generando un deterioro y perjuicio de la calidad de vida y del bienestar de las mujeres.

Consecuencias en la vida de las mujeres cuidadoras

Las mujeres cuidadoras dedican mayor esfuerzo y mayor tiempo al trabajo tanto productivo y reproductivo que los hombres, lo implica sacrificar sus tiempos de descanso en detrimento de su salud y un perjuicio de su propio bienestar.

La mayoría de las mujeres cuidadoras se sienten cansadas, saturadas, con la salud postergada, descuidada, vida personal y social abandonada, trabajos abandonados, ingresos y horarios laborales reducidos, ajustados y perjudicados, viven violencia y discriminación social.

Salud deteriorada y tiempo de descanso afectado

No puedo seguir bien mi tratamiento (de salud). De repente, me siento muy cansada, debe ser por el peso de cargarle (pcd). Me siento saturada. Hasta depresión tengo$\mathrm{MC} 2$

Normalmente duermo seis horas. Otras dos o tres horas, a veces estoy sin dormir cuando trabajo a la noche, me voy con él al PENDIF, descanso ahí o en el camino y me voy otra vez a trabajar sin dormir. Mis días libres son exclusivamente para mi hijo (pcd) $-\mathrm{MC}_{5}$

Vida laboral postergada, condiciones de trabajo precarizadas

Yo trabajaba antes. Trabajaba en ese entonces como ayudante de costura. Tenía mis propios ingresos. Hasta que me embarace de mi hijo (pcd) estaba trabajando, después de tenerle a él ya me fue imposible volver a trabajar. - $\mathrm{MC}_{3}$

\section{Vida personal, familiar y social postergada}

Desde que nació mi hijo, mi vida marital fue muy escasa, luego nos abandonó, nos divorciamos, ahora tiene exclusión de hogar por violencia familiar. Yo ya no estoy preparada socialmente para irme nomás a un evento social, no tengo esas ganas de arreglarme. - $\mathrm{MC}_{4}$

\section{Viven violencia y discriminación social}

El guardia del shopping le cerró la puerta y me dijo que él no puede entrar acá con la silla, porque acá no 
es parque de diversión para silla de ruedas $-\mathrm{MC}_{5}$

Vida cotidiana y las acciones de resistencia

La vida cotidiana de las mujeres cuidadoras se desarrolla entre las tareas domésticas y las tareas de cuidados que requieren los cuidados de cada persona dependiente por discapacidad;

A las 5:40 apu'avẽ. Ha upéi ajapoma la che tarea ape ha añatende che membyre (pcd), todo el día, ha toda la semana. - $\mathrm{MC} 1$

(A veces las 6 o 5:40 pero a las 5:40 me suelo levantar más. Y después ya hago mis tareas aquí y atiendo de mi hijo (pcd), todo el día y toda la semana $\mathrm{MC}$ )

Generalmente nos levantamos las 5;30, pero cuando voy a entrar a trabajar a la mañana, me levanto a las 04:30. Preparo y desayunamos. Voy al trabajo mientras mi hija (mayor) le lleva a mi hijo (pcd) al Pendif. Al volver, cenamos, nos preparamos para dormir, pero antes ya debo organizary encaminar todo para el día siguiente. $-\mathrm{MC}_{5}$

Acciones y Estrategias cotidianas de Resistencia en los cuidados de PcD

En esta cotidianeidad de tareas, las mujeres crean, desarrollan e implementan una gama de acciones y estrategias cotidianas de resistencia, pero de forma individual, es decir, son estrategias de carácter personal, aisladas y desarticuladas que no forman parte de estrategias organizativas o dealgún sistema público y nacional de cuidado. Estas acciones de resistencias son el replanteamiento de los objetivos y misión de vida, la planificación y organización, lo actitudinal y lo espiritual, y las acciones como la gestión o el jeporeka, el relacionamiento familiar-la comunicacióndialogo, la capacitación-formación en los cuidados.

- Fijar objetivos, proyecto de vida; Mi objetivo es lograr que mi hijo (pcd) tenga cada día una mejor calidad de vida, esto es mi lucha- $\mathrm{MC}_{5}$

Mi meta es verlo a él (hijo pcd) libre, libre y yo también. - $\mathrm{MC}_{4}$

- Organización y Planificación;

Yo soy muy perfeccionista, planifico todo, la organización es la base. Yo tengo totalmente programado lo que tengo que hacer para que me alcance las 24 horas- $\mathrm{MC}_{4}$

- Jeporeka - Autogestión;

Che ajeporeka, aike ha asẽ cualquier ladogui. - $\mathrm{MC} 1$

(Me rebusco, entro y salgo de cualquier lugar- $\mathrm{MC}_{1}$ )

Me autogestionó y hablo. Tenes que saber hablar y saber pedir. Yo me manejo con autogestión $\mathrm{MC}_{4}$

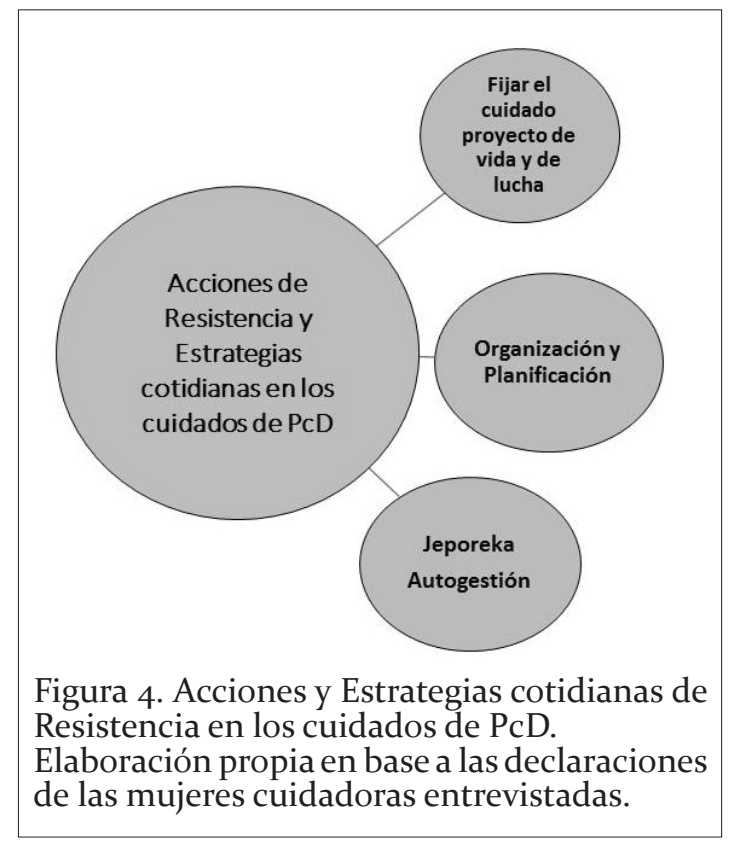

\section{Conclusiones}

El imaginario social y las prácticas sociales de las mujeres en su rol de cuidadoras de las personas dependientes por discapacidad están influidos por figuras, imágenes nacionales, actitudes construidos 
social y culturalmente en base a la división sexual del trabajo, con los cuales explican, justifican, refuerzan y reproducen los roles y espacios atribuidos tradicionalmente a lo masculino y lo femenino, vinculando al hombre con el rol proveedor de los medios económicos de supervivencia así como asociando la maternidad y los cuidados como una función natural e inmutable de las mujeres, asumiendo las responsabilidades y tareas de los cuidados sin posibilidad de optar.

El trabajo de cuidado es el eje central y fundamental de trabajo reproductivo, es lo que garantiza la reproducción social de la fuerza de trabajo, sin embargo, en sociedades capitalistas aliado al sistema patriarcal y machista basadas en la división sexual del trabajo, se privilegia a los hombres y se prioriza la acumulación y el consumo, lo relacionado a los cuidados sigue siendo atribuido a lo femenino como un trabajo de menor valor social y económico, por lo que no se reconoce la sobrecarga y las consecuencias que esto implica en la en la vida de las mujeres. El trabajo productivo y reproductivo de las mujeres cuidadoras implica un aumento de las de las jornadas laborales y de explotación, considerando el desigual e inequitativo reparto de los roles, los espacios, los tiempos, los trabajos y los ingresos de las mujeres con relación a los hombres. Por lo que ante la ausencia de políticas sociales y económicas que equilibren la vida laboral y familiar de las personas, las mujeres desarrollan una serie de estrategias y acciones cotidianas de resistencias de carácter individual, insuficientes y desarticuladas de una estrategia colectiva organizada o de una estrategia nacional de la que se haga cargo el Estado a partir de sistemas o políticas de cuidados.

Sin sobrecargar más responsabilidades sobre las familias y las mujeres, el protagonismo que las mujeres tienen para conducir la vida de sus familias y que las acciones de las mujeres influyen en las prácticas de los demás miembros de la familia tiene un potencial transformador y debe reconocerse como una oportunidad para la construcción de nuevos significados de las figuras y prácticas sociales desde la misma familia.

Es necesario preocuparse y ocuparse de los cuidados ampliando el debate académico, social y político a nivel nacional que permita avanzar en el consenso social sobre las responsabilidades de cuidados.

$\mathrm{Si}$ la sociedad y el Estado no intervienen las prácticas cotidianas desde la familia a través de políticas económicas y sociales que garanticen y promuevan la igual distribución de responsabilidades y tareas de cuidados se seguirá perjudicando la vida y el bienestar de las personas, principalmente de las mujeres.

\section{Referencias Bibliográficas}

Alayón, N., \& Molina, M. (2007). La desigual social: desarrollo y desafíos del Trabajo Social desde la Reconceptualización en América Latina. Textos y Contextos Porto Alegre, 6(1), p. 34-68. http:// revistaseletronicas.pucrs.br/ojs/index. php/fass/article/viewFile/1044/3231

Bagnato, M., Da Cunha, H., \& Falero, B. (s.f.). Sistema de cuidados en el área de personas con discapacidad. http://www.sistemadecuidados. gub.uy/innovaportal/file/13540/1/ presentacion_dis

Batthyány, K. (2007). Articulación entre vida laboral y vida familiar. Las prácticas de cuidado infantil de trabajadoras asalariadas de Montevideo. En M. A. Gutiérrez \& CLACSO (Eds.), Género, familias y trabajo: rupturas y continuidades. Desafíos para la investigación política. http:// bibliotecavirtual.clacso.org.ar/ar/ libros/grupos/gutierrez/o7Batthyany. pdf

Espino, A. (2012). Perspectiva Teórica sobre género, el trabajo y situación del mercado laboral latinoamericano. En V. Esquivel, A. Espino, L. Pérez, C. Rodríguez, S. Salvador, \& Vásconez, A. (Eds.), La economía feministas desde América Latina. Una hoja de ruta sobre los debates actuales en la 
región (p. 190-246). Santo Domingo: ONU Mujeres. http://www.unwomen. org/ /media/Headquarters/Media/ Publications/es/Economiafeminis tadesdeamericalatina.pdf

Esquivel, V. (2012). Cuidado, Economía y agendas políticas: Una mirada conceptual sobre la "organización social de cuidado" en América Latina. En En V. Esquivel, A. Espino, L. Pérez, C. Rodríguez, S. Salvador, \& Vásconez, A. (Eds.), La economía feministas desde América Latina. Una hoja de ruta sobre los debates actuales en la región (p. 141-246). Santo Domingo: ONU Mujeres. http://www.unwomen. org/ /media/Headquarters/Media/ Publications/es/Economiafeminis tadesdeamericalatina.pdf

Esquivel, V. (2011). La economía del cuidado en América Latina: poniendo a los cuidadosenelcentrodelaagenda.PNUD. http://www.americalatinagenera.org/ es/documentos/Atando_Cabos.pdf

Hernández Sampieri, R. et al. (2006). Metodología de la Investigación (4- ed.). México: McGraw-Hill Interamericana.

Iamamoto, M. (2003). El Servicio Social en la contemporaneidad. Sao Paulo: Corteza .

ONU Mujeres. (2010). Cadenas Globales de cuidado. Santo Domingo, Rca. Dominicana: Investigación y Capacitación de Naciones Unidas para la Promoción de la Mujer (UNINSTRAW).

ONU Mujeres. (2014). Por qué nos preocupamos de los cuidados. Nueva York: Centro de Capacitaciones.
Organización de las Naciones Unidas, PNUD, Cooperazione Italian. (s.f.). Criar, trabajar, cuidar.

Paraguay. Ministerio de Justicia \& Trabajo, STP, Ministerio de la Mujer, Vice Ministerio de la Juventud. (2013). Características y condiciones del trabajo doméstico remunerado en el Paraguay. Conociendo una realidad invisible. Asunción: UNFPA.

Pereira, P. A. (2003). Perspectivas teóricas sobre la cuestión social y el servicio socia. Revista Temporalis, Ano IV. ABEPSS, 1(7). http://www.fts.uner. edu.ar/academica/ccc/archivos/ catedras/1er_cuatrimestr e_2009/ CSeIP/CSeIP_Potyara_Pereira_ Cuestion_social_1.pdf

Piedra Guillen, N. (2004). Relaciones de poder: leyendo a Foucault desde la perspectiva de género. Revista de Ciencias Sociales, 6(106), 123-141. http:// www.redalyc.org/pdf/153/15310610.pdf

Rodríguez Enríquez, C. (2008). ¿Cuánto hay de economía en la economía del cuidado? En A. Gómez, (Ed.), De sol a sombra: el trabajo de las mujeres al cuidado de los otros (p. 16-21). Santiago, Chile: Red de salud de las mujeres Latinoamericanas y del Caribe - RSMLAC.

Soto, C., González, M., \& Bobree, P. (2012a). La migración femenina paraguaya en las cadenas globales de cuidados en Argentina. ONU Mujeres.

\section{Sobre el Autor}

Romilio González Chamorro

Licenciado en Trabajo Social, egresado con honores de la Universidad Nacional de Asunción - UNA, investigador social, consultor independiente y docente en colegios secundarios. Trabajos anteriores en áreas de la gerencia social, planificación estratégica, diseño e implementación de políticas, programas y proyectos sociales en el sector público y privado. 